\title{
Inhibition of the AIF/CypA complex protects against intrinsic death pathways induced by oxidative stress
}

\author{
N Doti ${ }^{\star, 1,2,3}$, C Reuther ${ }^{2}$, PL Scognamiglio ${ }^{1}$ AM Dolga ${ }^{2}$, N Plesnila ${ }^{*, 3,4}$, M Ruvo ${ }^{1}$ and C Culmsee ${ }^{*, 2}$
}

Delayed neuronal cell death largely contributes to the progressive infarct development and associated functional impairments after cerebral ischemia or brain trauma. Previous studies exposed a key role for the interaction of the mitochondrial protein apoptosis-inducing factor (AIF) and cytosolic cyclophilin A (СуpA) in pathways of programmed cell death in neurons in vitro and in vivo. These studies suggested that pro-apoptotic activities of AIF, such as its translocation to the nucleus and subsequent DNA degradation, depend on the physical interaction of AIF with CypA. Hence, this protein complex may represent a new pharmacological target for inhibiting the lethal action of AIF on the brain tissue. In this study, we show that the AIF amino-acid residues 370-394 mediate the protein complex formation of AIF with CypA. The synthetic AIF(370-394) peptide inhibited AIF/CypA complex formation in vitro by binding CypA with a $K_{\mathrm{D}}$ of $12 \mu \mathrm{M}$. Further, the peptide exerted pronounced neuroprotective effects in a model of glutamate-induced oxidative stress in cultured HT-22 cells. In this model system of AIF-dependent cell death, the AIF(370-394) peptide preserved mitochondrial integrity, as detected by measurements of the mitochondrial membrane potential and quantification of mitochondrial fragmentation. Further, the AIF(370-394) peptide inhibited perinuclear accumulation of fragmented mitochondria, mitochondrial release of AIF to the nucleus and glutamate-induced cell death to a similar extent as CypA-siRNA. These data indicate that the targeting of the AlF-CypA axis is an effective strategy of neuroprotection.

Cell Death and Disease (2014) 5, e993; doi:10.1038/cddis.2013.518; published online 16 January 2014

Subject Category: Neuroscience

Apoptosis-inducing factor (AIF) is a mitochondrial flavoprotein with several functions regulating cellular survival or death at the mitochondrial level. ${ }^{1}$ AIF has a role in the maintenance of mitochondrial electron transport chain functions, in the mitochondrial regulation of ROS formation, and in mitochondrial pathways of cell death, particularly in neurons. ${ }^{2,3}$ AIF deficiency in mouse and human cells hampers oxidative phosphorylation, likely through an effect on the biogenesis and maintenance of respiratory complexes I, III and IV, which ultimately results in decreased respiratory activity., Harlequin ( $\mathrm{Hq}$ ) mice, exhibiting an 80-90\% global reduction in AIF protein expression levels, suffer from slow, progressive neurodegeneration, ataxia, and loss of vision. ${ }^{1,3}$ These findings propose a vital role for AIF in the maintenance of mitochondrial functions and neuronal survival. In contrast, AIF acquires a detrimental role in release from the mitochondria under conditions of lethal cellular stress. There is evidence for a prominent role of AIF in mediating neuronal cell death in a variety of different rodent models of acute brain injury induced by cerebral hypoxia/ischemia $(\mathrm{HI})$, middle cerebral artery occlusion, cardiac arrest-induced brain damage, epileptic seizures or even brain trauma. In these models AIF translocation from the mitochondria to the nucleus was associated with chromatin condensation and large-scale DNA fragmentation in dying neurons. ${ }^{6-9}$

Inhibition of mitochondrial AIF release to the nucleus or reduction of AIF expression, such as in $\mathrm{Hq}$ mice, is neuroprotective and significantly reduces brain damage in the respective mouse models of acute brain damage. ${ }^{9-12}$ Despite the findings on the crucial role of AIF in mitochondrial pathways of caspase-independent neuronal death, attempts for direct inhibition of AIF to achieve neuroprotective effects have not been reported and pharmacological inhibitors of AIF are not available.

\footnotetext{
${ }^{1}$ Institute of Biostructures and Bioimaging (IBB)-CNR, CIRPEB, Via Mezzocannone, 16, Naples 80134, Italy; ${ }^{2}$ Institute of Pharmacology and Clinical Pharmacy, Philipps University of Marburg, Marburg 35032, Germany; ${ }^{3}$ Department of Neurodegeneration, Royal College of Surgeons in Ireland, Dublin 2, Ireland and ${ }^{4}$ Institute for Stroke and Dementia Research (ISD), University of Munich Medical School-Campus Großhadern, Max-Lebsche Platz 30, Munich D-81377, Germany

*Corresponding author: N Doti, Institute of Biostructures and Bioimaging (IBB)-CNR, CIRPEB, Via Mezzocannone, 16, Naples 80134, Italy. Tel: +39 0812536644 ; Fax: +39 081 2534574; E-mail: nunzianna.doti@cnr.it

or N Plesnila, Institute for Stroke and Dementia Research (ISD), University of Munich Medical School-Campus Großhadern, Max-Lebsche Platz 30, Munich 81377, Germany. Tel: +49 0897095 8357; Fax: +49 0897095 8369; E-mail: nikolaus.plesnila@med.uni-muenchen.de

or C Culmsee, Institute of Pharmacology and Clinical Pharmacy, Philipps University of Marburg, Karl-von-Frisch-Straße 1, Marburg 35032 , Germany. Tel: +49 0 6421 2825963; Fax: +49 06421 2825720; E-mail: culmsee@ staff.uni-marburg.de

Keywords: AIF/CypA complex; mitochondria; neuronal death; oxidative stress; peptide inhibitor

Abbreviations: AIF, apoptosis-inducing factor; ANOVA, analysis of variance; CCCP, carbonyl cyanide m-chlorophenylhydrazone; CsA, cyclosporin A; CypA and D, cyclophilin A and D; DiOC6(3), 3,3'-dihexyloxacarbocyanine iodide; FACS, fluorescent-activated cell sorting; FITC, fluorescein isothiocyanate; Fmoc, fluorenylmethoxycarbonyl; IMM, inner mitochondrial membrane; JC-1, 5,5',6,6'-tetrachloro-1,1',3,3'-tetraethylbenzimi-dazolylcarbocyanine-iodide; TMRE, tetramethylrhodamine ethyl ester; MMP, mitochondrial membrane permeabilization; MTT, 3-(4,5-dimethylthiazol-2-yl)-2,5-diphenyltetrazolium bromide; OMM, outer mitochondrial membrane; RT-PCR, reverse transcription-PCR; siRNA, small interfering RNA

Received 26.6.13; revised 28.10.13; accepted 15.11.13; Edited by D Bano
} 
A direct approach to inhibit AIF-mediated cell death in neurons may be achieved by inhibiting the interaction of AIF with cyclophilin A (CypA). On release from the mitochondria, AIF binding to CypA is supposed to initiate the translocation of both proteins to the nucleus, where they generate a lethal DNA-degrading complex. ${ }^{13,14}$ CypA exerts peptidyl-prolylisomerase activity in vitro; however, its function is unknown in living cells. ${ }^{15-18}$ In neurons, CypA is expressed in the cytoplasm and in the nucleus, where it can exert apoptosisrelated DNase activity. ${ }^{17}$

The molecular model of the AIF/CypA complex ${ }^{13}$ suggested that the interaction involves the AIF regions 367-399 and one of the AIF helices (aa. 136-146), together with a part of the $\beta$-barrel of CypA. ${ }^{13}$ The predicted interface overlaps neither with the catalytic site of CypA nor with the predicted binding site for Hsp70, nor with the DNA-binding site on AIF. This is in agreement with experimental evidence showing that CsA and Hsp $70^{19}$ fail to inhibit the CypA-AIF interaction in pull-down experiments. ${ }^{13}$ All data strongly suggest that inhibiting AIF/CypA complex formation is an effective strategy to block the lethal action of AIF without interfering with its vital functions.

Here, we designed AIF peptides targeting the AIF-binding site on CypA and characterized the inhibition of AIF/CypA complex formation by SPR measurements using recombinant proteins in vitro and in living cells by co-immunoprecipitation assays. To evaluate the neuroprotective potency of such complex inhibitors in living cells, we applied the AIF peptide and CypA-siRNA in HT-22 neuronal cells, where glutamate toxicity and AIF-dependent cell death is mediated independently of ionotropic glutamate receptors by oxidative stress. ${ }^{20}$

\section{Results}

Identification of the minimal sequence of tAIF with retained CypA binding. AIF/CypA interaction has been suggested from experiments in cell extracts and living cells. ${ }^{13,14,21}$ We further characterize their interaction by the SPR/BIAcore technology ${ }^{22}$ using the full-length CypA and the pro-apoptotic form of $\operatorname{AIF}(\operatorname{AIF}(\Delta 1-121)$; named tAIF) (Supplementary Figures $1 \mathrm{~A}$ and $\mathrm{B}){ }^{23,24}$ Results confirmed the direct interaction between CypA and tAIF, giving a $K_{\mathrm{D}}$ value of $75 \times 10^{-9} \mathrm{M}$ (Figure $1 \mathrm{a}$ ).

Next, starting from the reported molecular model of the AIF/CypA complex, ${ }^{13}$ we designed and prepared two AIF peptides, corresponding to the predicted interface between the two proteins (Supplementary Figures 1C-E). Peptides AIF(340-363) and AIF(370-394) were tested by SPR competition-binding assays for their ability to prevent tAIF/ CypA complex formation (Figure 1b). Although AIF(370-394) inhibited complex formation in a dose-dependent manner with an $\mathrm{IC}_{50}$ of $3.0 \times 10^{-6} \mathrm{M}$, AIF(343-360) tested in the same concentration range was ineffective (Figure $1 \mathrm{~b}$ ).

We also performed direct SPR-binding experiments to the immobilized proteins. Sensorgrams obtained for AIF(370-394) binding to CypA clearly indicated a very high affinity for CypA (Figure 1c, $K_{D}=1.2 \times 10^{-5} \mathrm{M}$ ). AIF(343-360) bound to CypA; however, it exhibited a 1000-fold reduced affinity compared with AIF(370-394), with a $K_{\mathrm{D}}$ value of $6700 \times 10^{-5} \mathrm{M}$ (Figure $1 \mathrm{~d}$ ). No affinity to tAIF was detected for both peptides at the applied concentration range.
Moreover, we investigated whether the binding of AIF (370-394) to CypA induces inhibitory effects on its catalytic activity. The CypA-mediated cis-trans isomerization of the Ala-Pro peptide bond in the peptide Suc-Ala-Ala-Pro-Phe4-nitroanilide was measured in a coupled assay with chymotrypsin, based on the ability of this protease to cleave only the trans isomer. ${ }^{18}$ The CypA-mediated hydrolysis of 4-nitroanilide, in the presence of AIF(370-394) peptide and CsA (used as control), was followed by the increase in absorbance at $390 \mathrm{~nm}$. Although CsA strongly inhibited CypA enzymatic activity, the AIF(370-394) peptide did not interfere with this activity (Supplementary Figure 1F).

These findings underscore that the amino-acidic region spanning residues 370-394 of AIF is predominantly involved in the binding to CypA and that AIF binds to CypA in an interface that does not overlap with the catalytic site of CypA, in agreement with previous observations. ${ }^{13}$

CypA has a crucial role in glutamate-mediated cell death. The treatment with high concentrations of glutamate $(2-5 \mathrm{mM})$ in HT-22 cells is a caspase-independent model of cell death mediated by AIF. ${ }^{25-27}$ In HT-22 cells, AIF was confined in the healthy mitochondria, whereas glutamate treatment caused AIF nuclear localization within about $12-14 \mathrm{~h}$ after the lethal insult (Supplementary Figures $2 \mathrm{~A}$ and $\mathrm{B}) .^{10,25,26,28}$

In this study, western blot analysis of nuclear extracts and fluorescent confocal imaging showed that CypA was detectable in both the cytosol and the nucleus of healthy HT-22 cells. Nevertheless, glutamate treatment induced a remarkable sequential translocation of CypA from the cytosol to the nucleus, as previously described in other model systems of neuronal death (Figure 2a; Supplementary Figure 2C). ${ }^{13}$ Interestingly, we observed a significant increase in СypA levels in the nucleus compared with control conditions, starting $6 \mathrm{~h}$ after onset of glutamate exposure, without significant differences in its cytosolic levels (Figure $2 b$ ).

Further, fluorescent confocal imaging revealed that AIF co-localized with CypA in damaged HT-22 cells in a range of 12-14 h after exposure to glutamate (Figure 2c), and this co-localization correlated with cell death determined by nuclear morphology after 4',6-diamidino-2-phenylindole dihydrochloride (DAPI) staining (Figure 2d). The glutamatepromoted interaction between proteins was confirmed by immunoprecipitation (IP) experiments, using total extracts of $\mathrm{HT}-22$ cells treated with $2 \mathrm{mM}$ glutamate for $12-14 \mathrm{~h}$ (Figure 2e; Supplementary Figure 2C).

We also tested whether CypA-siRNA-mediated gene silencing (Figure 3a) altered glutamate-induced nuclear translocation of AIF using confocal microscope analysis. In accordance with previous results obtained in a $\mathrm{HI}$ model in CypA knockout mice in vivo, ${ }^{13,14}$ siRNA-CypA prevented AIF translocation to the nucleus of $\mathrm{HT}-22$ cells despite the glutamate challenge (Figure 3b). Further, CypA-siRNA provided a full protection against glutamate-induced cell death as demonstrated by MTT assays, real-time impedance measurements and flow cytometry analysis of HT-22 cells double stained with FITC-Annexin-V/propidium iodide (PI) (Figures 3c-e).

$A$ recent work established that alkylating DNA-damagemediated PCD requires the nuclear interaction between AIF 
a
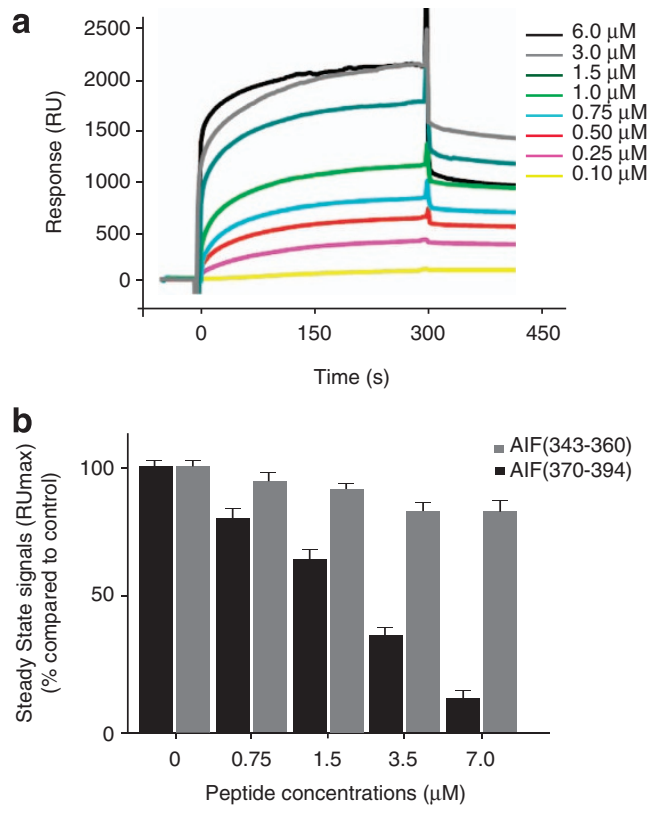

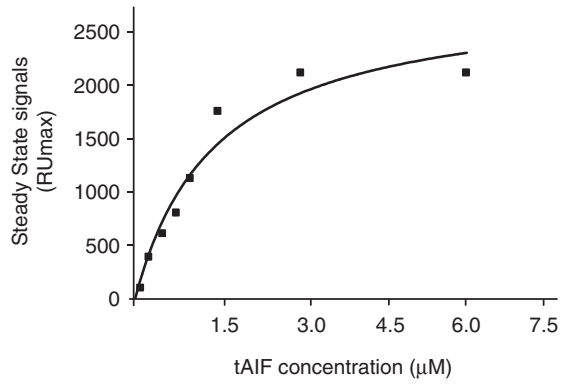

C

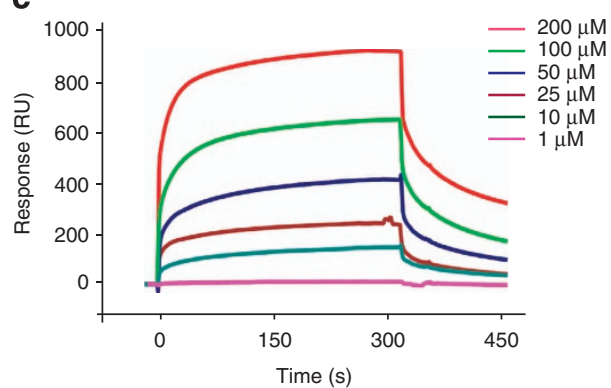

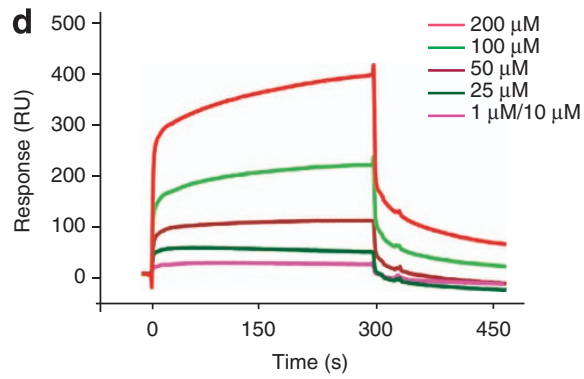

Figure 1 The peptide AIF(370-394) blocks the interaction between AIF and CypA by binding to CypA. (a) SPR sensorgrams resulting from the injection of tAIF at the indicated concentrations onto immobilized CypA. In the right panel the tAIF concentration-dependency of the steady-state binding response is shown. (b) Competition-binding experiments by SPR are reported. Peptides at increasing concentrations were mixed with tAIF at $0.75 \mu \mathrm{M}$ and injected on the immobilized CypA. AIF(370-394) peptide blocked the interaction between the two proteins, whereas the $\operatorname{AIF}(343-360)$ peptide had no effect on the complex formation. Results are presented as the steady-state signals $\left(\mathrm{RU}_{\max }\right)$ versus peptide concentration. In (c and d) SPR sensorgrams are reportedly obtained by injection of AIF peptides at the indicated concentrations on the CypA-immobilized sensor chip. AIF(370-394) binds to the immobilized protein with a $K_{\mathrm{D}}$ in the low-micromolar range, whereas AIF(343-360) shows only a very weak affinity (1000-fold lower compared with the AIF(370-394) peptide)

and $\mathrm{H} 2 \mathrm{AX}$ and that this association is critical in the generation of a DNA-degrading complex that also implicates CypA. ${ }^{21}$ Thus, we tested the responsiveness of $\mathrm{H} 2 \mathrm{AX}$ depletion in HT-22 to glutamate treatment. The downregulation of H2AX by siRNA did not abrogate glutamate toxicity, suggesting that the interaction of CypA, AIF and H2AX occurs depending on the paradigm of cellular stress (Supplementary Figures $3 A-C$ ).

Overall, our results are compatible with the proposed molecular mechanism of AIF/CypA-mediated death signaling, suggesting that the glutamate-induced direct interaction between CypA and AIF is crucial for AIF-mediated cell death in $\mathrm{HT}-22$ cells during oxidative stress.

AIF(370-394) restores survival in glutamate-treated HT-22 cells. Next, we investigated whether the peptide AIF(370-394) antagonizes the detrimental effect of the AIF/CypA complex in the model of glutamate toxicity.

AIF(370-394) transfected in HT-22 (Supplementary Figures $4 \mathrm{~A}-\mathrm{B})$, significantly inhibited the neuronal cell loss at concentrations between 10 and up to $50 \mu \mathrm{M}$. The protection ranged from 70 to $80 \%$ at the highest concentration tested, as demonstrated by MTT, Annexin-V/PI double staining and realtime impedance measurements on HT-22 cells exposed to glutamate (Figures $4 a, c$ and d). In contrast, no protection was detected in glutamate-treated cells when AIF(343-360) or an unrelated peptide (NC) was applied as negative control (Figures 4a and b).

These results show that the AIF(370-394) inhibitory peptide provides a significative neuroprotection against glutamate-induced cell death.

AIF(370-394) blocks AIF and CypA nuclear translocation. To further investigate the protective effects mediated by AIF(370-394), we evaluated whether it influences the cellular localization of either AIF or CypA by confocal microscopy analysis. As shown in Figure 5a, AIF(370-394) $(50 \mu \mathrm{M})$ blocked glutamate-induced nuclear translocation of AIF to an extent comparable to that observed after siRNA-mediated CypA silencing in the HT-22 cells (Figure $3 b$ ). Moreover, the peptide binding CypA (Figure 5b) 
a

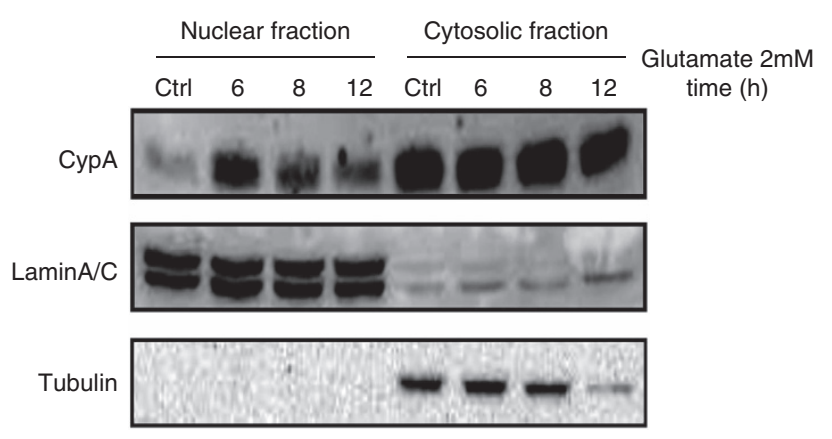

c
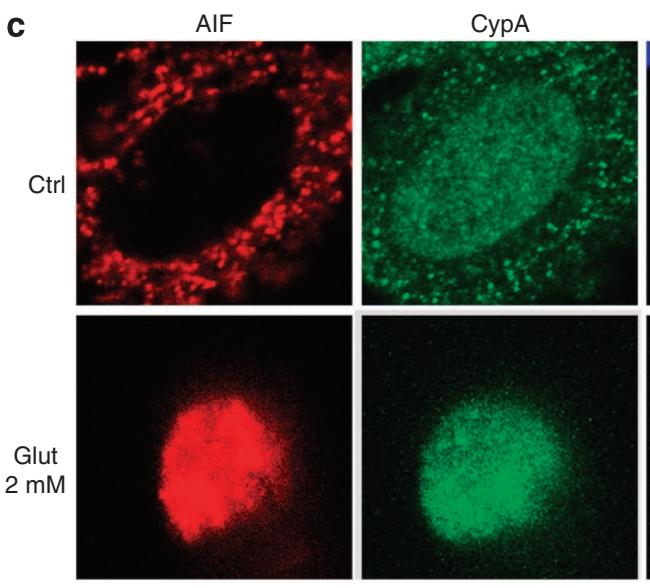

e

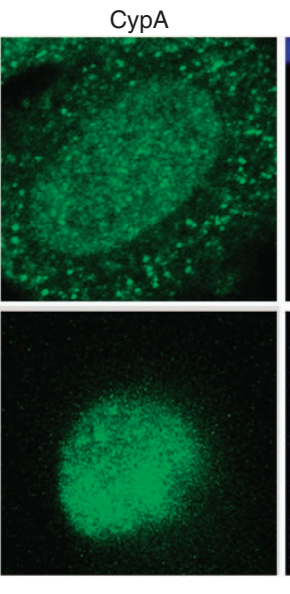

e Ip anti-AIF

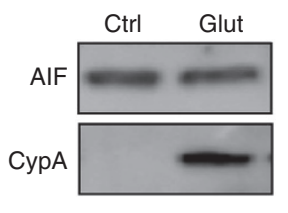

b
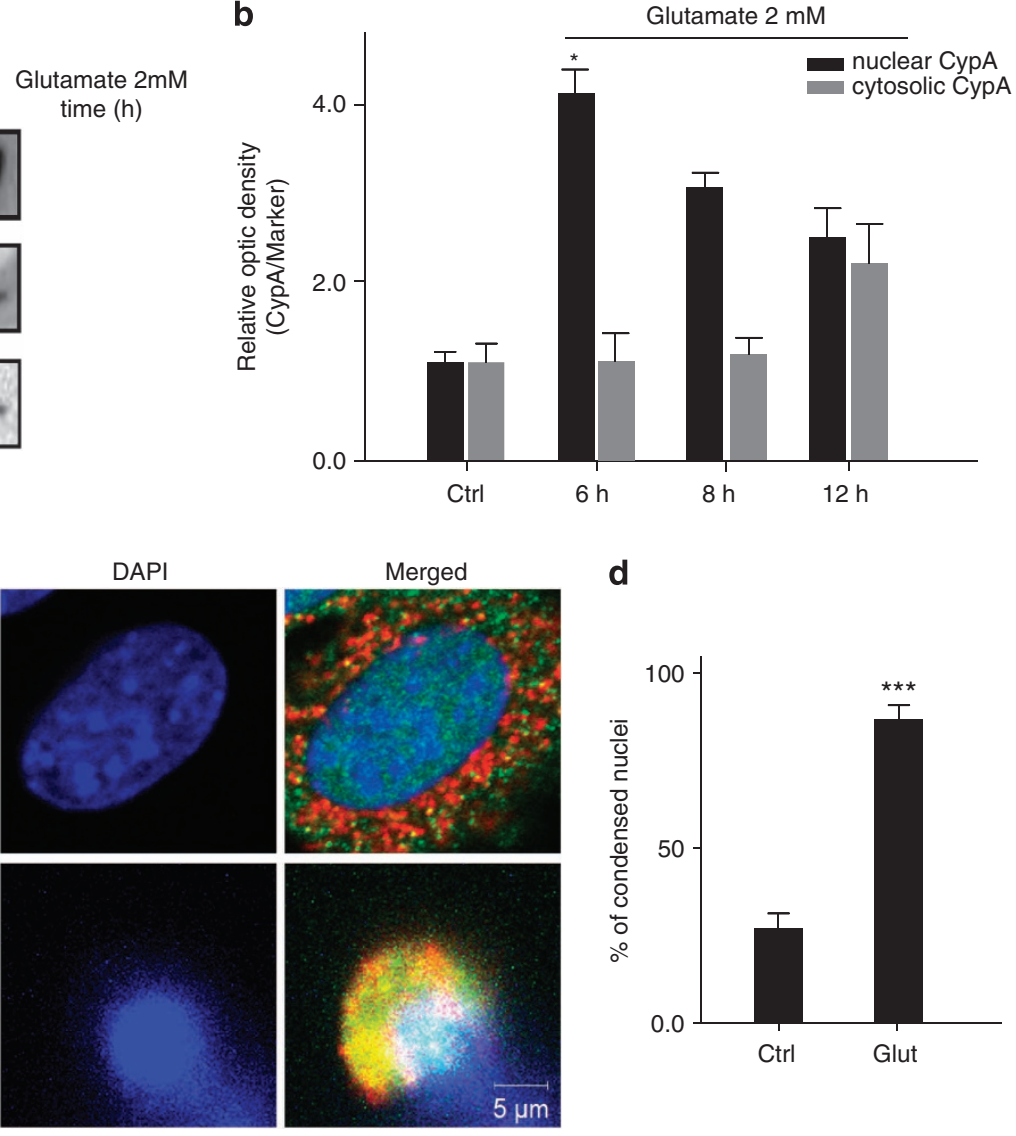

d

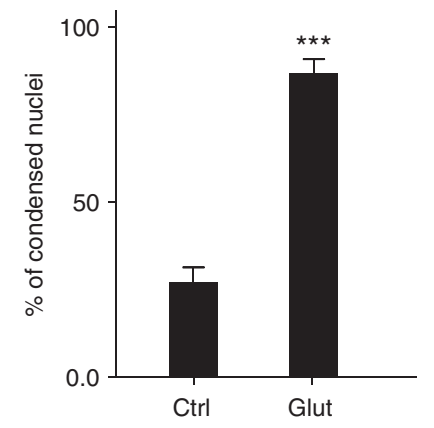

Figure 2 CypA regulates glutamate-mediated HT-22 cell death. (a) Western blot analysis of CypA (18 kDa) content in the nuclear and cytosolic fraction of HT-22 cells either untreated or treated with $2 \mathrm{mM}$ glutamate for 6,8 and $12 \mathrm{~h}$. As shown, CypA levels persistently increased in the nucleus with a peak at $6 \mathrm{~h}$. Lamin A/C ( $80 \mathrm{kDa})$ and tubulin ( $55 \mathrm{kDa}$ ) were used as nuclear and cytosolic markers, respectively. (b) Densitometric analysis of the bands obtained $0,6,8$, and $12 \mathrm{~h}$ after glutamate treatment. Bars represent the mean \pm S.D. of three independent experiments $\left({ }^{*} P<0.05\right)$. (c) Confocal immunofluorescence detection of AIF and CypA in apoptotic HT-22 cells compared with untreated cells showing that the two proteins timely colocalize following the apoptotic insult (see merged image). Scale bar: $5 \mu \mathrm{m}$. (d) HT-22 cells were treated with glutamate (Glut, $12-14 \mathrm{~h}$ ) and stained with DAPI to visualize nuclei. Data are reported as average \pm S.D. $(n=4),{ }^{* \star \star} P<0.001$. (e) Co-immunoprecipitation of AlF and CypA in glutamate-treated (2 mM for 12-14h) and untreated cells. After immunoprecipitation of AIF and immunodetection of AIF or CypA, we found that CypA was captured only in apoptotic cells (upper panel). The panel on the right shows a western blot analysis of the total amount of AlF and CypA, using the tubulin protein as a loading marker

prevented glutamate-induced CypA nuclear translocation, whereas the NC did not preclude AIF and CypA nuclear translocations as well as in control cells (Figure 5a).

Experiments to address the presence of AIF in the cytosol did not provide a clear-cut evidence of a significant enrichment of the protein in the cytoplasmic fraction after either administration of AIF(370-394) or downregulation of CypA during oxidative stress (Figure $5 \mathrm{c}$ ).

AIF(370-394) and CypA silencing preserve OMM integrity. Previous studies showed that glutamate induces the opening of the mitochondria permeability transition (MPT) pore, resulting in dissipation of the mitochondrial membrane potential $(\Delta \psi \mathrm{m})$ across the inner mitochondrial membrane (IMM). ${ }^{27}$ The dysfunction of mitochondria leads to an energy crisis and promotes the release of pro-apoptotic factors such as AIF. 25,26,28 To further evaluate AIF(370-394)-mediated effects in HT-22 cells, we assessed mitochondrial function and energy status in glutamate-treated HT-22 cells, by using the fluorescent dyes JC-1 and TMRE. ${ }^{29,30}$ In line with previous results in $\mathrm{HT}-22$ cells, JC-1 fluorescence indicated that there is a decrease of $\Delta \psi \mathrm{m}$ within $12-14 \mathrm{~h}$ after 
glutamate treatment ${ }^{25,28}$ and that this effect is significantly attenuated in cells transfected with the peptide AIF(370-394) and the CypA-siRNA (Figures 6a and b; Supplementary Figure 5A).

The loss in the $\Delta \psi \mathrm{m}$ is characterized by mitochondrial swelling and fragmentation. ${ }^{25,26,28}$ Such mitochondrial fragmentation was significantly attenuated in cells transfected with the active peptide or with CypA-siRNA (Figures $6 \mathrm{c}$ and $\mathrm{d}$; Supplementary Figure 5B). In contrast, HT-22 cells transfected with the NC or with the unrelated siRNA (siCtrl) showed mitochondrial fragmentation after glutamate exposure (Figures 6c and d; Supplementary Figure 5B).

Mitochondria actively transport $\mathrm{Ca}^{2+}$ into the matrix via a uniporter driven by the electrochemical proton gradient. ${ }^{31}$ $\mathrm{Ca}^{2+}$ accumulation in the mitochondrial matrix leads to loss in $\Delta \psi \mathrm{m}$ with the consequent release of pro-apoptotic proteins. Glutamate induces a dose-dependent increase in intracellular $\mathrm{Ca}^{2+}$ concentrations, which is an important hallmark of neuronal cell death (Supplementary Figure 6A). ${ }^{31,32}$ In this model system, the increase in the cytoplasmic concentration of $\mathrm{Ca}^{2+}$ cannot be completely attributed to its influx from the extracellular space but it is dependent also on organelles such as mitochondria and endoplasmic reticulum. ${ }^{31}$ Indeed, the removal of $\mathrm{Ca}^{2+}$ from the culture medium only partly prevented the glutamate-mediated cell death. Therefore, we decided to investigate whether the AIF (370-394)-mediated positive effect on mitochondria was associated with a restored rise of $\mathrm{Ca}^{2+}$. The detection of intracellular $\mathrm{Ca}^{2+}$ levels reveled that either AIF(370-394) pretreatment or the downregulation of CypA significantly restored $\mathrm{Ca}^{2+}$ concentrations despite glutamate exposure (Figure 7a; Supplementary Figure 6B). Moreover, the delivery of the active peptide and CypA-siRNA provided additive protective effects to depletion of extracellular $\mathrm{Ca}^{2+}$ (Figure 7b). These findings showed that the protective effects afforded by the targeting of CypA-AIF axis were achieved independently of the extracellular $\mathrm{Ca}^{2+}$ influx into the cells, but could be associated with a protective effect at the level of mitochondrial bioenergetics.

To further characterize the effect of AIF(370-394) peptide on the loss in $\Delta \psi \mathrm{m}$, we induced the opening of the MPT pore in isolated mitochondria.

The carbonyl cyanide $m$-chlorophenyl hydrazone (CCCP) induced strong loss of $\Delta \psi \mathrm{m}$ in isolated mitochondria (Figure 7c) and this effect is inhibited by CsA. ${ }^{32}$ Mitochondria were isolated from HT-22 cells and incubated with AIF (370-394), NC peptides or CsA (used as control). Then mitochondria were treated with $\mathrm{CCCP}$, and the MPT pore opening was assessed by DiOC6 staining. Although CsA inhibited loss in $\Delta \psi \mathrm{m}$, the AIF(370-394) as well as the NC peptide did not provide a positive effect on MPT pore opening in response to CCCP action (Figure 7c). Our cumulative data therefore indicate that $\operatorname{AIF}(370-394)$ provided anti-apoptotic effects not via a direct effect on MPT pore opening.

\section{Discussion}

Here, we provide evidence that the delivery of the peptide AIF(370-394), corresponding to an amino-acidic region of AIF interacting with CypA, induces neuroprotection by inhibiting the AIF-CypA axis. This is supported by several evidences. First, similar to the downregulation of CypA, the delivery of AIF(370-394) drastically reduces the sensitivity of glutamatemediated oxidative stress in neuronal cells. Second, AIF (370-394) blocks the nuclear translocation of AIF and CypA, the key event in the caspase-independent cell death mechanism. Third, the active peptide provides protection against glutamate-mediated mitochondrial dysfunction and reduces the sustained increase in intracellular $\mathrm{Ca}^{2+}$.

One of the most puzzling conundrum in the AIF-mediated cell death field concerns the observation that the nuclear translocation of AIF can depend or not on its association with CypA in the cytosol. Currently, two different models have been proposed to explain this lethal event. One model proposes that the lethal translocation of AIF to the nucleus requires its interaction with CypA in the cytosol. ${ }^{13}$ In support of this hypothesis, it was reported that the nuclear translocation of AIF was significantly reduced in a model of perinatal $\mathrm{HI}$ in $\mathrm{CypA}^{-1-}$ mice compared with wild-type mice. ${ }^{13}$ Further, in AIF-deficient mice carrying the $\mathrm{Hq}$ mutation, CypA staining in the nucleus was reduced after injury and this correlated well with protective effects in models of cerebral ischemia. In a second model, also corroborated by experimental evidence, ${ }^{21}$ it is instead proposed that AIF and CypA independently translocate in the nucleus, where they regulate chromatinolysis and programmed necrosis by generating an active DNAdegrading complex involving the $\mathrm{H} 2 \mathrm{AX}$ as well. ${ }^{21}$ Indeed, the downregulation of CypA in MEF cells does not arrest nuclear translocation of AIF but reduces DNA damage. These controversial data suggest that the molecular events for caspase-independent cell death depend on the cell type and the kind of apoptotic stimulus.

Here, we confirm previous observations of glutamatemediated AIF release from the mitochondria to the nucleus in HT-22 cells. ${ }^{25,28}$ We extended these findings by showing that in this model system glutamate induces the association between AIF and CypA and that specific targeting of CypA by a selective siRNA completely abrogates AIF nuclear translocation. This latter event is significantly inhibited even when CypA is targeted in the cytosol by AIF(370-394), indicating the crucial involvement of CypA in the nuclear translocation of AIF and then in glutamate-mediated cell death. In addition, we demonstrate that the glutamate-mediated cell death is exclusively dependent on the interaction between AIF and CypA. Indeed, no protection is observed when the histone $\mathrm{H} 2 \mathrm{AX}$ is downregulated.

The simplest interpretation of our findings is that during oxidative stress in HT-22 cells AIF is released from the mitochondria to the cytosol, where it interacts with CypA. The complex then translocates in the nucleus where, in line with previous observations, ${ }^{13}$ it induces cell death.

Interestingly, we observe that one of the first responses to oxidative stress is the rapid accumulation of CypA in the nucleus some hours before AIF mitochondrial release. This suggests the intriguing possibility that CypA might serve as both an AIF carrier and as a signaling platform to control cell death on glutamate exposure in neuronal cells.

This hypothesis is supported by the observation that selective targeting of CypA provides positive effects on the mitochondrial bioenergetics. 


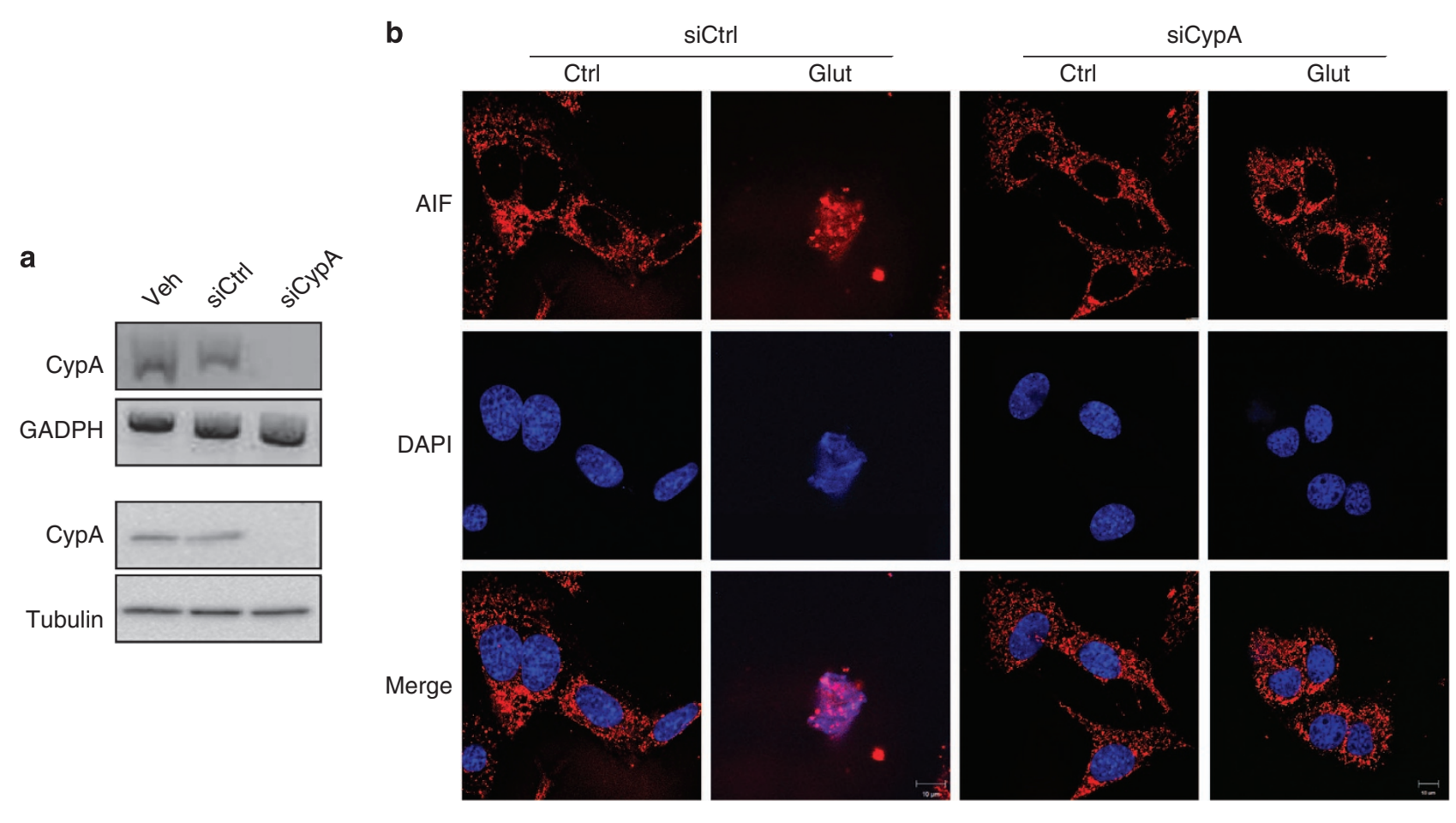

C

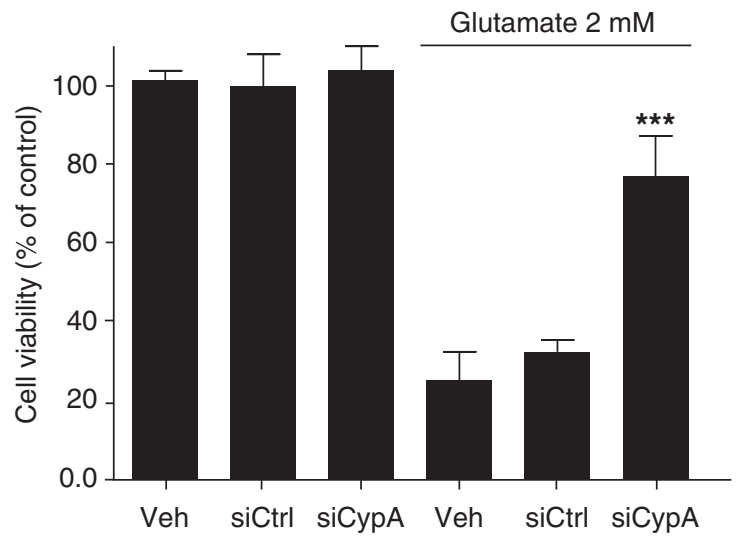

d

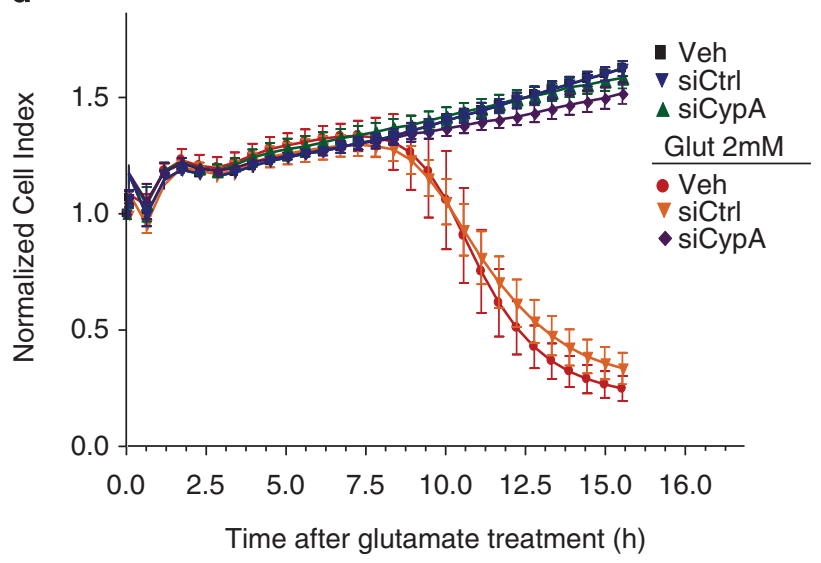

e

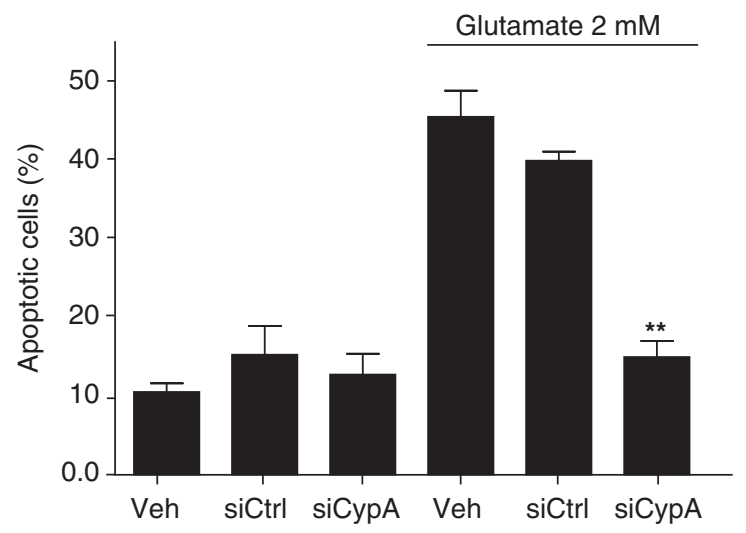


We have previously shown that mitochondria have a crucial role in the glutamate-mediated oxidative stress model system. ${ }^{25,28}$ The loss in $\Delta \psi \mathrm{m}$ is a perquisite for the neuronal loss mediated by glutamate. We now observe that delivering AIF(370-394) to HT-22 cells before glutamate insults significantly blocks the loss of $\Delta \psi \mathrm{m}$ induced in mitochondria by glutamate.

Glutamate-induced intracellular $\mathrm{Ca}^{2+}$ overload has been widely hypothesized to have a role in releasing mitochondrial inter-membrane space proteins, including AIF, by permeability transition-induced outer membrane rupture. We now show that the delivery of the CypA-binding AIF peptide, as well as the downregulation of CypA, significantly attenuates the increase of intracellular $\mathrm{Ca}^{2+}$ concentration on glutamate exposure, also in agreement with the positive effect induced on mitochondria. Apparently, this is independent from reduced calcium influxes from the extracellular environment, because the active peptide provides effects that are additive to the removal of extracellular $\mathrm{Ca}^{2+}$ mediated by reduced activation by the calcium-dependent protease calpain. ${ }^{33}$

To explain these findings, we hypothesize that AIF (370-394) might interfere with the processes regulating $\Delta \psi \mathrm{m}$, and/or with the increase of mitochondria influx of $\mathrm{Ca}^{2+}$, thereby preserving mitochondrial integrity and function.

To assess this aspect, we tested the effects of AIF (370-394) peptide on the $\Delta \psi \mathrm{m}$ loss induced in isolated a
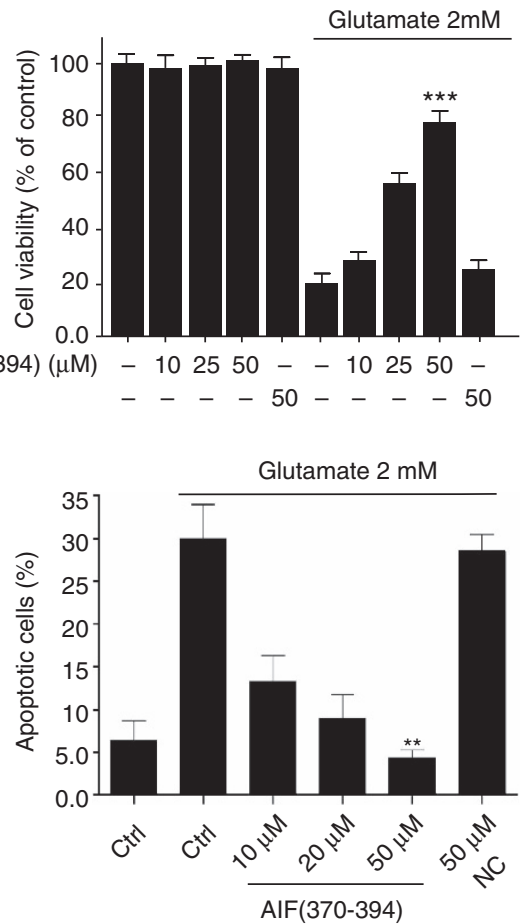

b

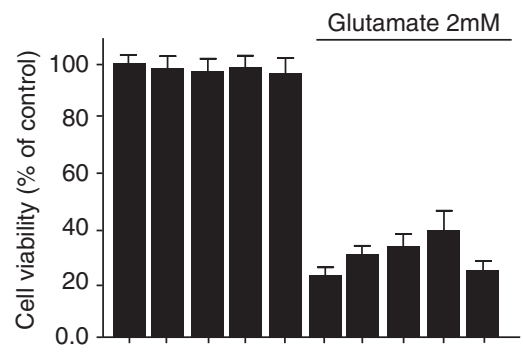

$\operatorname{AIF}(343-360)(\mu \mathrm{M})-102550--102550-$

$\mathrm{NC}(\mu \mathrm{M}) \quad-\quad-\quad 50-\ldots-50$

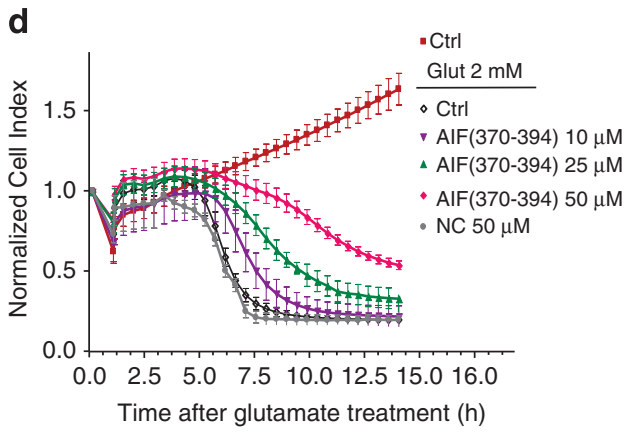

Figure 4 AIF(370-394) delivery abrogates glutamate-mediated cell death. (a and $\mathbf{b}) \mathrm{HT}-22$ cells were transfected with three doses of AIF(370-394) or AIF(343-360) peptides $(10 \mu \mathrm{M}, 25 \mu \mathrm{M}, 50 \mu \mathrm{M})$ or with an unrelated peptide (NC), used as negative control, at the highest concentration tested $(50 \mu \mathrm{M})$. Cell viability after glutamate treatment $(2 \mathrm{mM}$ for $12 \mathrm{~h}$ ) was assessed by the MTT assay. As shown, only the presence of AIF(370-394), which binds to CypA, protected cells from the glutamate-induced death in a concentration-dependent manner. Results are presented as percentage of controls considered to be $100 \%$ and represent the mean \pm S.D. of at least four independent experiments performed in quadruplicate. (c) To confirm that apoptosis occurred in glutamate-treated cells and that peptide protection influenced this process, peptide-transfected HT-22 cells were treated with $2 \mathrm{mM}$ glutamate $(12 \mathrm{~h})$ or untreated (control) and labeled with Annexin-V-FITC/PI. Finally, they were analyzed by flow cytometry. As shown, the number of apoptotic cells was strongly diminished in the presence of increasing concentrations of AIF(370-394). Percentages reported in the bar graph refer to double-positive stained cells $(n=4)$. (d) HT-22 cells were treated with $2 \mathrm{mM}$ glutamate after transfection with AIF(370-394) or with an unrelated peptide used as negative control (NC). Data show that up to $15 \mathrm{~h}$ from the initial glutamate-induced damage, AIF(370-394) afforded protection in a time- and dose-dependent way

Figure 3 Deletion of CypA prevents the apoptotic process. (a) HT-22 cells were transfected with scrambled siRNA (siCtrl) or with siRNA against mouse CypA (siCypA). Total cell lysates from siRNA-treated cells were prepared and the mRNA levels and expression levels of CypA were assessed by RT-PCR (upper panel) and immunoblotting (lower panel), respectively. Expression levels of CypA were significantly reduced in cells transfected with the specific siRNA against the protein. (b) Immunofluorescent labeling of AIF (red) and nuclei (DAPI, blue) in HT-22 cells transfected with siCtrl or siCypA, followed by exposure to $2 \mathrm{mM}$ glutamate for $12 \mathrm{~h}$ (Glut) as indicated. CypA-downregulated HT-22 cells showed very weak nuclear AIF staining in injured cells. (c) Cell viability assessed by the MTT assay in wild-type and CypA knockdown HT-22 cells treated or untreated (control) with $2 \mathrm{mM}$ glutamate for $12 \mathrm{~h}$. Data show that wild-type cells (treated with vehicle) or with the siCtrl underwent apoptosis on glutamate insult, whereas those expressing reduced levels of CypA were more resistant to the glutamate challenge. MTT results are presented as percentage of control, considered to be $100 \%$, and represent mean \pm S.D. of three independent experiments. (d) Cell mortality in CypA-downregulated HT-22 cells on glutamate treatment $(2 \mathrm{mM}$ at $0 \mathrm{~h}, n=8)$ was also assessed over a time period of about $15 \mathrm{~h}$ by impedance measurement. Data show again that cells underwent apoptosis by glutamate only in the presence of CypA. Cell death in wild-type and CypA-blunted cells was also analyzed by Annexin-V-FITC/PI double staining (e), showing that apoptosis was abrogated when CypA expression was silenced by specific siRNA. Data are reported as mean \pm S.D. ${ }^{* *} P<0.01,{ }^{* * *} P<0.001$ compared with $2 \mathrm{mM}$ glutamate-treated cells $(n=3$ independent experiments, Anova Bonferroni test) 

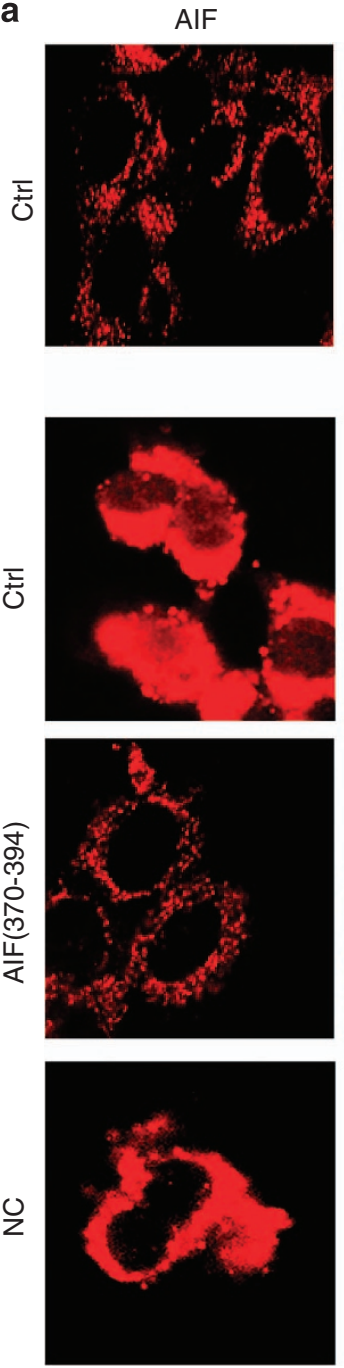

b

Ip AIF(370-394)

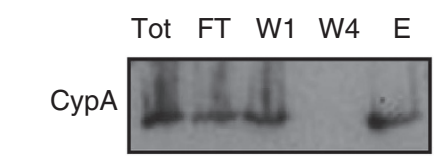

Ip NC

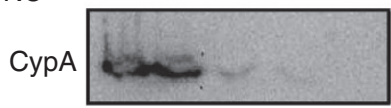

СурА
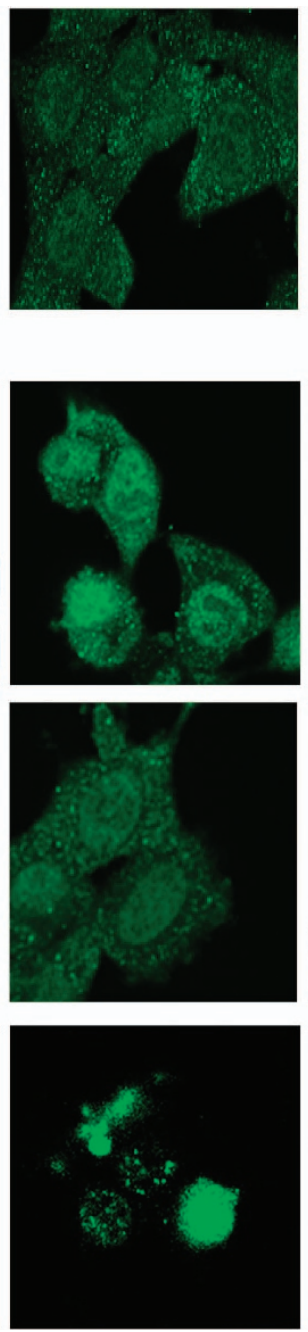

C
DAPI
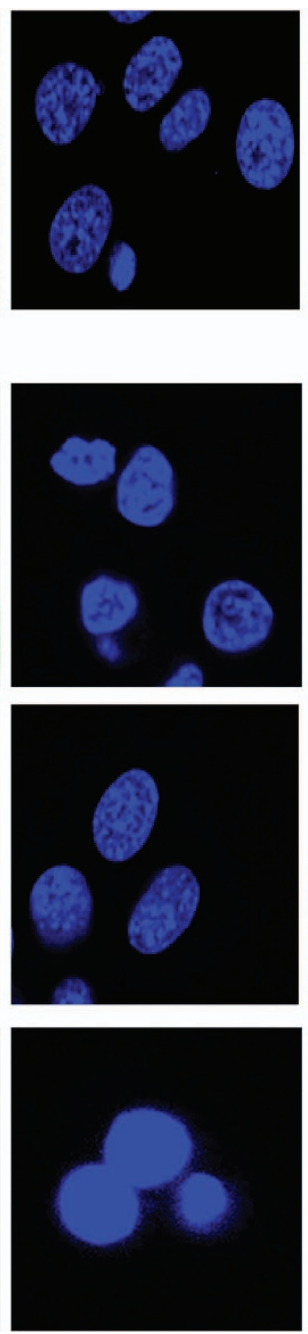

Cytosolic fraction
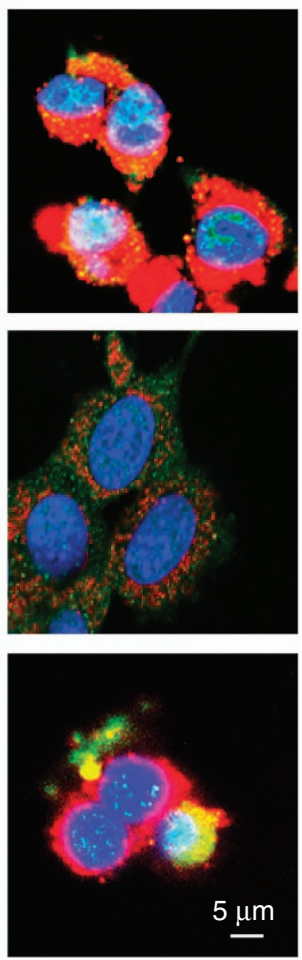

Glutamate $2 \mathrm{mM}$

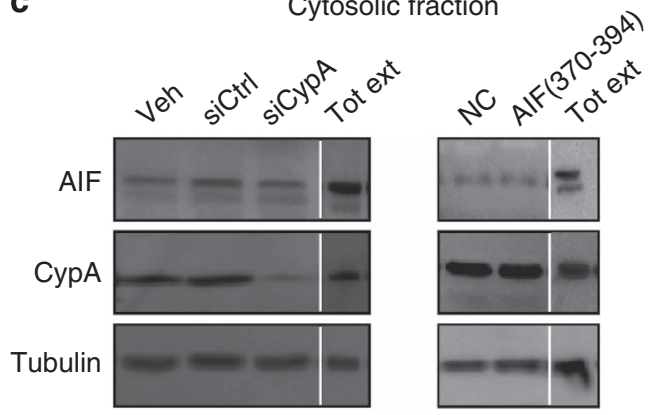

Glutamate $2 \mathrm{mM}$

Glutamate $2 \mathrm{mM}$

Figure 5 AIF(370-394) delivery abrogates the nuclear translocation of AIF. To see whether the CypA-binding peptide could block translocation of both proteins following glutamate treatment, $\mathrm{HT}-22$ cells were transiently transfected with $50 \mu \mathrm{M}$ of either AIF(370-394) or NC and then exposed to $2 \mathrm{mM}$ glutamate or control buffer for $12 \mathrm{~h}$. Following immunostaining for AIF and CypA and examination by confocal microscopy, we found that only AIF(370-394) at the indicated concentration effectively prevented nuclear translocation of both proteins. (b) Immunoprecipitation experiments of AIF(370-394) and CypA in HT-22 cells. After immobilization of peptides on the resins and their incubation of HT-22 total extracts, the immunodetection of CypA, we found that CypA was captured only by AIF(370-394) (upper panel, lane E) peptide and not by NC (lower panel, lane E); (c) Cytosolic fraction recovered from wt, AIF(370-394) and siCypA transfected HT-22 cells after glutamate treatment in a range of 12-14 $\mathrm{h}$ were blotted for AIF detection. Compared with the cytosolic level of AIF in control cells (Veh, siCtrl, NC), glutamate treatment does not induce a significant increase of AlF in the cytosol 
a

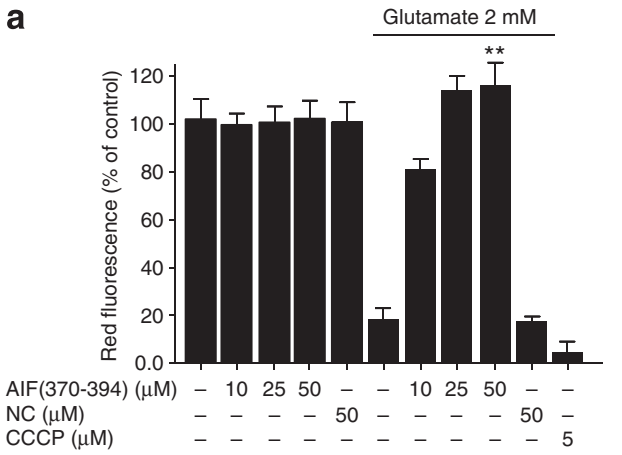

b

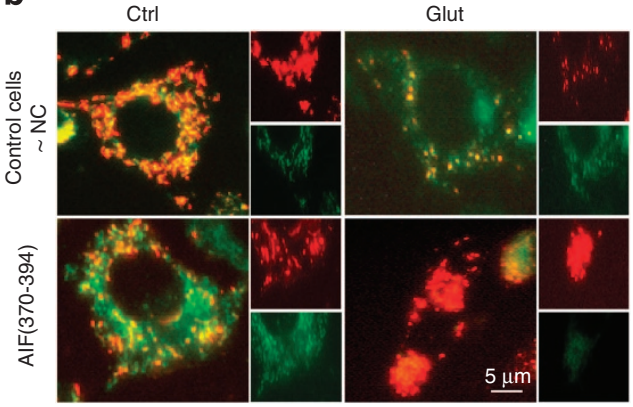

C

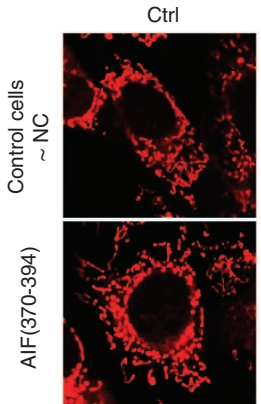

Glut

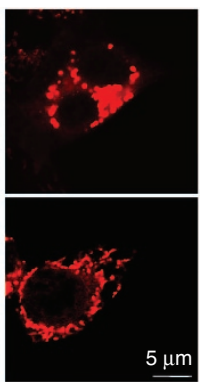

d

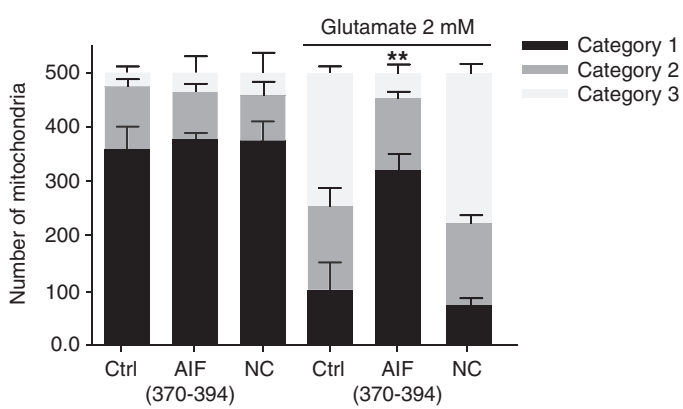

Figure $6 \mathrm{AIF}(370-394)$ peptide treatment provides protection at the level of mitochondria. (a) After $12 \mathrm{~h}$ post glutamate treatment, wild-type and transfected $\mathrm{HT}$-22 cells were labeled with JC-1 or TMRE, and the frequency of cells with $\Delta \psi \mathrm{m}$ loss was assessed by FACS analysis (a) and by fluorescence microscopy (b). Data show that the treatment of cells with the active peptide before the glutamate insult was sufficient to block loss of the red fluorescence, otherwise to what happens in control cells or cells transfected with the NC peptide. Data presented in the bar chart (a) are means of three independent experiments \pm S.D. and are expressed as percentage of control considered as $100 \%$. (c) Fluorescence photomicrographs of mitochondria in HT-22 cells transfected with AIF peptides, with and without glutamate exposure (2 mM) for $12-14 \mathrm{~h}$ as indicated. As shown, peptide-treated cells recovered a more physiological mitochondrial morphology that instead appeared either fragmented or circular in control cells or cells transfected with the NC. (d) Quantification of mitochondrial morphology of $\sim 500$ cells per condition: category 1 (elongated tubulin-like structure), category 2 (intermediate length) and category 3 (fragmented mitochondria). ${ }^{\star \star} P<0.01$ compared with $2 \mathrm{mM}$ glutamate-treated cells $(n=3$ independent experiments, ANOVA, Bonferroni test)

mitochondria by CCCP. We observed that the pharmacological targeting of CypA did not counteract the uncoupling action of CCCP compared with the well-known cyclophilin's inhibitor CsA. This observation excludes a direct protective effect of the peptide on the MPT pore opening mediated by proteins in the IMM, thus suggesting the view that its antiapoptotic activity derives from its interaction with CypA.

The protein CypA has PPlase activity; it accelerates the slow step of proline cis-trans isomerization in peptides and unfolded proteins, in vitro. PPlases were shown to be involved in widespread cellular events such as protein folding and trafficking of proteins, immunosuppression, HIV replication and cell division in living cells. ${ }^{34}$ Most of these pathways are sensitive to the inhibitory effect of CsA on CypA.

On the basis of these evidence, we have also addressed whether the peptide could interfere with the catalytic activity of CypA, thereby provoking collateral effects owing to pharmacological targeting of the enzyme. Remarkably, the peptide, unlike the CsA, does not alter the catalytic activity of CypA in in vitro biochemical experiments. This implies that AIF (370-394) and CsA very likely recognize two non-overlapping sites or induce allosteric effects on CypA, as previously hypothesized, ${ }^{13}$ and that the anti-apoptotic ability of AIF (370-394) cannot be associated with an inhibition of CypA catalytic activity.
On the basis of these data, we hypothesize a mechanism by which oxidative insults in HT-22 cells induce first the nuclear translocation of CypA and then, in a second step, a substantially fast mitochondria-assisted release of AIF. Released AIF is shuttled to the nucleus by CypA, where it catalyzes DNA fragmentation and induces apoptosis. This model of AIF-dependent death signaling is supported by the mere observation that a soluble peptide, by targeting the AIF-binding site on CypA and seemingly preventing the formation of the CypA-AIF complex, abrogates the perinuclear condensation of mitochondria and the consequential AIF mitochondrial release.

Such recruitment of mitochondria to the nuclei of damaged cells could be accelerated through the interaction of cytoplasmatic or perinuclear CypA with the AIF fraction loaded on the OMM. ${ }^{35}$ From these perinuclear mitochondria, AIF can rapidly translocate into the nucleus after cleavage from the OMM by calpain- $1,{ }^{36}$ which is also localized in the nucleus and is activated by elevated levels of $\mathrm{Ca}^{2+} \cdot 33$ Importantly, the peptide induces a significant dose-dependent mitoprotection without direct effects on mitochondria, thus suggesting alternative mechanisms of mitochondrial function recovery in this cellular setting and a possible interference with the CypA-dependent mechanisms in the cytosol and in the nucleus. Notably, this model also explains why AIF is only 


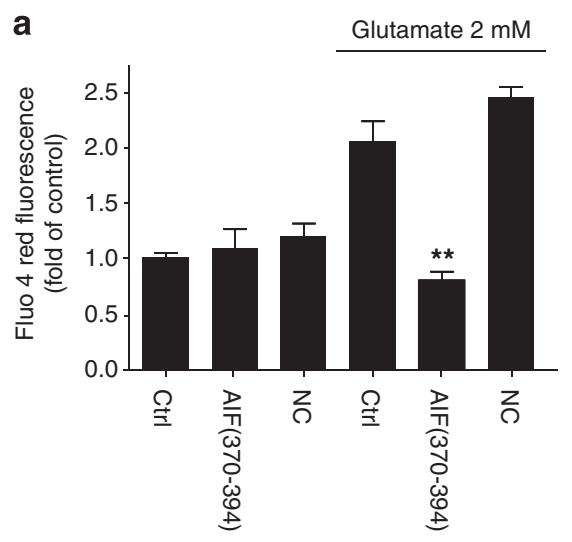

b

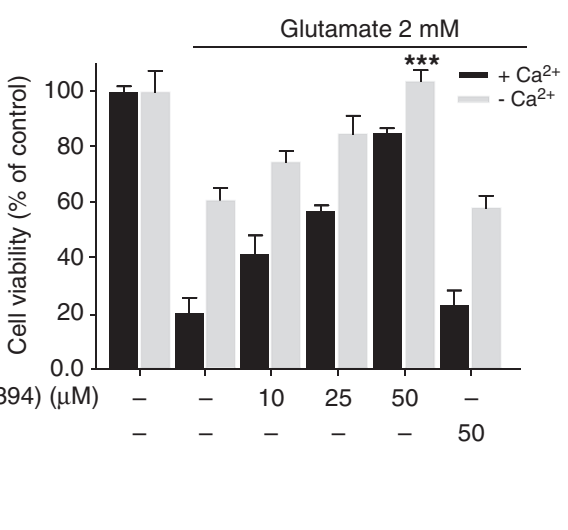

C

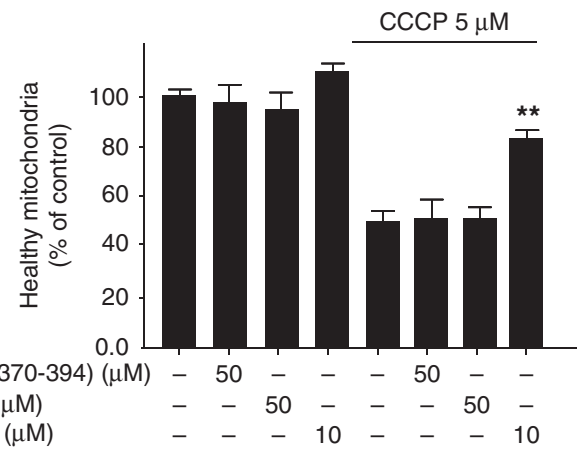

Figure 7 CypA-siRNA and AIF(370-394) peptide block the oxidative stress-induced increase of intracellular Ca2 + concentration. (a and b) HT-22 cells were treated with $2 \mathrm{mM}$ glutamate for $12-14 \mathrm{~h}$. The intracellular concentration of $\mathrm{Ca}^{2+}$ was assessed by the fluorescent $\mathrm{Ca}^{2+}$ indicator Fluo-4 AM in 96 -well plates. (b) Cell viability assessment of HT-22 cells received $\operatorname{AIF}(370-394)$ peptide at the indicated concentrations, followed by exposure to $2 \mathrm{mM}$ glutamate for 12-14h, either in a standard culture medium (black bars) or in a medium without $\mathrm{Ca}^{2+}$ (gray bars) $\left(n=4,{ }^{* \star \star} P<0.001\right)$. (c) Mitochondrial membrane depolarization induced with $50 \mu \mathrm{M}$ CCCP in isolated mitochondria from HT-22 cells. Equal amounts of pure mitochondria were incubated or not (Ctrl) with peptides at concentrations of $50 \mu \mathrm{M}$ and then treated with CCCP. CsA at a concentration of $10 \mu \mathrm{M}$ was used as a positive control. Data show that AIF(370-394) as well as NC, differently to CsA, did not prevent the CCCP-mediated mitochondrial depolarization $\left(n=4,{ }^{\star \star} P<0.01\right)$

poorly detected in the cytosol during oxidative stress and why no increase of protein levels is detected following peptide treatment.

It should be noted, however, that alternative mechanisms cannot be ruled out. Our model, indeed, does not explain why the protective effects provided by the AIF peptide or by CypA gene silencing are exerted upstream of mitochondrial permeabilization and AIF release, rather than downstream of AIF release, at the level of AIF transport to the nucleus.

This new finding significantly broadens the protective effects of CypA inhibition and their neuroprotective potential, as the protection of mitochondria induced upstream of AIF release is much stronger than that deriving from the inhibition of AIF nuclear entry alone.

The oxidative stress is an important factor contributing to delayed neuronal death after acute brain injury by cerebral ischemia or brain trauma, and in neurodegenerative diseases, such as Parkinson's disease and Alzheimer's disease. The present model of glutamate toxicity in mouse HT-22 cell line is well established and widely used for in vitro studies of neuronal death induced by oxidative stress. ${ }^{20,25,26,28}$ As mentioned, the pathogenesis of neurodegenerative disorders is induced by multiple factors, such as $\mathrm{Ca}^{2+}$ overload, ROS production and mitochondrial dysfunction. Therefore, multitarget strategies are required for drug leads to achieve a sustained neuroprotection or to render effective the treatments for neurodegenerative diseases. We here demonstrate that the targeting of CypA by a peptide targeting the AIF-binding site on CypA acts as a multitarget neuroprotectant without apparent toxicity effects, and could therefore display advantageous pharmacological profiles.

\section{Materials and Methods}

Antibodies. The following antibodies were used for immunostaining and western blot analysis: anti-actin actin clone $\mathrm{C} 4$ mouse mAb (MB Biomedicals, GmbH, Eschwege, Germany, no. 691001); anti-AIF(D20) goat pAb (Santa Cruz, Santa Cruz, CA, USA, no. sc-9416); anti-CypA rabbit pAb (Cell Signaling, Danvers, MA, USA, no. 2175); anti-CoxIV rabbit pAb (Cell Signaling, no. 4844); anti-Tubulin rabbit pAB (Cell Signaling, no. 2148); anti-Tim23 mouse pAb (BD Pharmingen, BD Bioscience Laboratories, Heidelberg, Germany, no. 611223); anti-LaminA/C rabbit pAb (Cell Signaling, no. 20353); and anti-Bid rabbit pAb (Cell Signaling, no. 2003).

siRNA. For RNA interference experiments the following siRNA sequences were used: mouse siRNA targeting CypA: siCypAFw $5^{\prime}$-CUGAAUGGCUGGAUGGCAA-3' and siCypARev 5'-UUGCCAUCCAGCCAUUCAG-3'; and a scrambled siRNA (siCtrl) used as negative control: 5'-AAGAGAAAAAGCGAAGAGCCA-3' (all Dharmacon, Thermo Scientific, Dreieich, Germany). siRNA targeting H2AX used is: siH2AX Fw 5'-GCGUCUUUGCUUCAGCUUG-3' and siH2AX Rev 5'-CAAGCUGAAGCAAAGACGC-3'.

Peptide synthesis and characterization. Reagents for peptide synthesis included Fmoc-protected amino acids and resins, activation and deprotection 
reagents, which were purchased from Calbiochem-Novabiochem (Laufelfingen, Switzerland) and InBios (Naples, Italy). Solvents for peptide synthesis and HPLC analysis were purchased from Romil (Dublin, Ireland); reversed-phase columns for peptide analysis and the LC-MS system were bought from ThermoFisher (Milan, Italy). Solid phase peptide synthesis was performed on a fully automated multichannel peptide synthesizer Syro I (Multisyntech, Germany) following the Fmoc methodology. ${ }^{37}$ Preparative RP-HPLC purification was carried out on a Shimadzu LC-8A pump (Columbia, MD, USA), equipped with an SPD-M10 AV detector and with a Phenomenex C18 Jupiter column (Torrance, CA, USA; $50 \times 22 \mathrm{~mm} \mathrm{ID;} 10 \mu \mathrm{m})$. LC-MS analyses were carried out on a LCQ DECA XP Ion Trap mass spectrometer equipped with an OPTON ESI source (Vernon Hills, IL, USA), operating at $4.2 \mathrm{kV}$ needle voltage and $320^{\circ} \mathrm{C}$ with a complete Surveyor HPLC system. This Surveyor HPLC system included an MS pump, an auto-sampler and a photo diode array. Narrow bore $50 \times 2 \mathrm{~mm} \mathrm{C18} \mathrm{BioBasic}$ LC-MS columns (Thermo Fisher) were used for these analyses. Peptides were labeled with Fluorescein- $\beta$ Ala at their N-termini for imaging studies.

SPR analysis. The BIAcore 3000 SPR system for the real-time binding assay and related reagents were purchased from GE Healthcare (Milan, Italy). CypA protein (Sigma-Aldrich, Taufkirchen, Germany, no. C3805) was immobilized at a concentration of $5 \mu \mathrm{g} / \mathrm{ml}$ in $10 \mathrm{mM}$ acetate buffer $\mathrm{pH} 4.0$ (with a flow rate of $5 \mu \mathrm{l} / \mathrm{min}$ and an injection time of $7 \mathrm{~min}$ ). The CypA immobilization was achieved on a CM5 Biacore sensor chip (GE Healthcare), using EDC/NHS(1-ethyl-3(3-dimethylaminopropyl)carbodiimide/ $\mathrm{N}$-hydroxysuccinimide) chemistry following the manufacturer's instructions. ${ }^{38}$ Residual reactive groups were deactivated by treatment with $1 \mathrm{M}$ ethanolamine hydrochloride, $\mathrm{pH}$ 8.5. A reference channel was prepared by activating with EDC/NHS compounds and deactivating with ethanolamine. Analyte injections of $90 \mu \mathrm{l}$ were performed at the indicated concentrations. BIAevaluation analysis package (version 4.1, GE Healthcare) implemented by the instrument software was used to subtract the signal of the reference channel and to evaluate kinetic and thermodynamic parameters of complexes. ${ }^{40} \mathrm{RU}_{\max }$ data versus peptide concentrations were fitted with GraphPad Prism, version 5.00, GraphPad Software (San Diego, CA, USA). Competitive SPR experiments with AIF peptides were carried out by pre-incubating AIF peptides with several concentrations of tAIF at the fixed concentration of $50 \mu \mathrm{M}$.

Cell culture and transfection. HT-22 neuronal cells were cultured at a density of $10000 \mathrm{cells} / \mathrm{well}$ in a 96-well plate (Greiner Bio-One, Frickenhausen, Germany) at $37^{\circ} \mathrm{C}$ and $5 \% \mathrm{CO}_{2}$ in Dulbecco's modified Eagle medium (Invitrogen, Karlsruhe, Germany) with $10 \%$ heat-inactivated calf serum and $100 \mathrm{U} / \mathrm{ml}$ penicillin, $100 \mu \mathrm{g} / \mathrm{ml}$ streptomycin and $2 \mathrm{mM}$ glutamine. Transient transfection with siRNA was performed using Lipofectamine-2000 reagent (Invitrogen) following the manufacturer's procedure. Peptide transient transfection was performed using the cationic lipid mixture Pro-Ject Protein Transfection Reagent kit according to the manufacturer's instructions (Pierce, Thermo Scientific, Munich, Germany, Prod no. 89850). ${ }^{39}$

Assessment of cell viability and apoptosis. Quantification of cell viability was performed by 3-(4, 5-dimethylthiazol-2-yl)-2, 5-diphenyltetrazolium bromide (MTT) reduction at a concentration of $0.5 \mathrm{mg} / \mathrm{ml}$ for $1 \mathrm{~h}$. The absorbance of each well was determined with an automated FLUOstar Optima reader (BMG Labtechnologies $\mathrm{GmbH}$, Offenburg, Germany) at $570 \mathrm{~nm}$ with a reference filter at $630 \mathrm{~nm}$. Control cell values were set to $100 \%$ cell viability, as absolute values may vary between experiments. For statistical analysis, experiments were repeated at least three times with an $n=8$ per condition. Apoptotic cell death was detected by Annexin-V/PI staining according to the manufacturer's instructions (Annexin-VFITC Detection Kit, PromoKine, Promocell, Heidelberg, Germany) and subsequent flow cytometry analysis. Apoptotic and necrotic cells were determined using FACScan (BD Bioscience, Heidelberg, Germany). Annexin-V-FITC was excited at $488 \mathrm{~nm}$ and emission was detected through a $530 \pm 40-\mathrm{nm}$ band pass filter Propidium iodide was excited at $488 \mathrm{~nm}$ and fluorescence emission was detected using a $680 \pm 30$-nm band pass filter. For statistical analysis, experiments were repeated at least three times. In addition, real-time detection of cell death was performed by measurements of cellular impedance by the xCELLigence system (Roche, Penzberg, Germany). ${ }^{41}$

RT-PCR. Total RNA was extracted using a Nucleospin RNAll kit (MachereyNagel, Düren, Germany) and one-step RT-PCR was performed with Superscript III One-Step RT-PCR (Invitrogen). Primers used for CypA, H2AX and GAPDH were: CypA forward primer, 5'-CCACCGTGTTCTTCGACATCACG-3'; CypA reverse primer, 5'-GCTCCTCTTGCCATTCCTGACCC-3'; H2AX forward primer, 5'-CCAC CTCCCTCACAGAAAG-3'; H2AX reverse primer, $5^{\prime}$-CCGGGAGGTATTCCTAGAG-3'; and GAPDH forward primer, 5'-CGTCTTCACCACCATGGAGAAGGC-3'; GAPDH reverse primer, 5'-AAGGCCATGCCAGTGAGCTTCCC-3'. PCR for CypA, H2AX and GAPDH were performed after CDNA synthesis at $60^{\circ} \mathrm{C}$ for $30 \mathrm{~min}$ and a denaturation at $95^{\circ} \mathrm{C}$ for $2 \mathrm{~min}$. PCR amplification was performed by 30 cycles, each with a denaturation for $30 \mathrm{~s}$ at $95^{\circ} \mathrm{C}$, annealing for $1 \mathrm{~min}$ at $57^{\circ} \mathrm{C}$ and elongation for $2 \mathrm{~min}$ at $70^{\circ} \mathrm{C}$. The final extension of the PCR products was performed at $70^{\circ} \mathrm{C}$ for $10 \mathrm{~min}$. RT-PCR products were visualized by a Bio-Rad gel detection system (ChemiDoc XRS, Bio-Rad, Karlsruhe, Germany) under UV illumination after electrophoresis on a 1.5\% agarose gel containing SybrGold (Invitrogen).

Subcellular fractionation and western blot analysis. For western blot analysis, HT-22 neurons were lysed with Tris $50 \mathrm{mM}$, Mannitol $0.25 \mathrm{M}$, EDTA $1 \mathrm{M}$, EGTA $1 \mathrm{M}, \mathrm{DTT} 1 \mathrm{mM}$, Triton X 1\%, pH 7.5 (all Sigma-Aldrich), supplemented with Complete Mini Protease Inhibitor Cocktail (Roche, Mannheim, Germany) and PMSF (phenylmethylsulfonylfluoride) (Sigma-Aldrich). After centrifugation at $15000 \times g$ for $15 \mathrm{~min}$ at $4{ }^{\circ} \mathrm{C}$, the supernatant was stored at $-80^{\circ} \mathrm{C}$ until further use. Nuclear extracts were separated from cytosolic fractions using the nuclear extract kit according to the manufacturer's instructions (Active Motif, Rixensart, Belgium). For mitochondrial extract preparations cells were resuspended in the lysis buffer $(20 \mathrm{mM}$ HEPES, $250 \mathrm{mM}$ sucrose, $3 \mathrm{mM}$ EDTA and $0.1 \mathrm{mM}$ PMSF supplemented with Complete Mini Protease Inhibitor Cocktail, $\mathrm{pH} 7.5$ ); followed by membrane disruption using a glass dounce and 15 passes with a $20-G$ needle. After centrifugation at $900 \times g$ for 10 min the supernatant was collected and the pellet was disrupted a second time. All steps were performed on ice. The supernatant was centrifuged at $16800 \times g$ for $10 \mathrm{~min}$ and the resulting pellet was resuspended in fresh buffer. Protein amounts were determined with the Pierce BCA kit (Perbio Science, Bonn, Germany). Cytosolic fractions were prepared as follows: cells were resuspended in the lysis buffer $(10 \mathrm{mM}$ HEPES, $0.32 \mathrm{M}$ sucrose, $2 \mathrm{mM}$ EDTA, pH 7.4 supplemented with protease and phosphatase inhibitors), followed by membrane disruption using a glass dounce and 15 passes with a $20-G$ needle. After centrifugation at $900 \times g$ for $10 \mathrm{~min}$ the supernatant was collected and centrifuged again at 50000 r.p.m. for $30 \mathrm{~min}$ to yield crude cytosolic material. Then fractions were concentrated to $\sim 50-75 \mu$ l.

After SDS-PAGE gel electrophoresis and protein transfer on a PVDF membrane, western blot analysis was performed incubating the blot with the specific antibody overnight at $4{ }^{\circ} \mathrm{C}$. Membranes were then exposed to the appropriate HRP-conjugated secondary antibody $(1: 2500$, Vector Laboratories, Burlingame, CA, USA) followed by a chemiluminescence detection. Protein loading was controlled by reprobing the membrane with a monoclonal anti- $\alpha$-tubulin antibody or anti-actin antibody. Chemidoc software (Bio-Rad, Munich, Germany) was utilized for detection and quantification of western blot protein signals.

Immunoprecipitation experiments. Cells were untreated or treated with glutammate (12-14 h). Then they were collected in IP buffer $(20 \mathrm{mM} \mathrm{Tris} / \mathrm{HCl}, \mathrm{pH}$ 7.4, $150 \mathrm{mM} \mathrm{NaCl}, 2 \mathrm{mM}$ EDTA, 10\% Glycerol, 1\% Triton X-100) supplemented with protease inhibitors (Roche). The extracts were incubated overnight at $4{ }^{\circ} \mathrm{C}$ with anti-AIF or anti-CypA beads-coupled antibody. The beads were washed with IP buffer and eluted for $10 \mathrm{~min}$ in the sample buffer $1 \times$ (Tris- $\mathrm{HCl} 20 \mathrm{mM}$, SDS $2.5 \%$, glycerol $5 \%$, DTT $5 \mathrm{mM}, 0.05 \%$ Bromophenol blue, $\mathrm{pH} 6.8$ ). For IP experiments with peptides, $4 \mathrm{mg}$ of $\operatorname{AIF}(370-394)$ peptide or $\mathrm{NC}$ were resuspended in the IP buffer (PBS $1 \times, \mathrm{pH} 7.4)$ and then incubated overnight at $4{ }^{\circ} \mathrm{C}$ with $500 \mu \mathrm{l}$ of NHS-agarose resin (PIERCE, no. 26196). After immobilization the resin was washed and then incubated for $16 \mathrm{~h}$ at $4{ }^{\circ} \mathrm{C}$ with HT-22 total extract. The resin was subsequently washed and proteins retained were eluted with the sample buffer.

Confocal images for mitochondrial protein redistribution. HT-22 cells treated or not with peptides or siRNA were seeded on eight-well-ibidi- $\mu$-slides (IBIDI, Munich, Germany). After exposure to glutamate insults (2 mM for 12-14 h) cells were fixed with $4 \%$ paraformaldehyde and permeabilized with Triton $X$ $0.04 \%$. Afterward, cells were incubated with various primary antibodies. The corresponding secondary antibodies included donkey anti-goat Alexa 568 and anti-rabbit Alexa 488 (Molecular Probes, Eugene, OR, USA). ${ }^{26}$ Then, cells were counterstained with the DNA-binding dye DAPI (Sigma-Aldrich). Images were acquired using a confocal laser-scanning microscope (Axiovert 200, Carl Zeiss, Jena, Germany). Light was collected through a $63 \times 1.4$-NA oil immersion objective. 
Evaluation of mitochondrial morphology. HT-22 cells were labeled with MitoTracker DeepRed according to the manufacturer's instructions (Invitrogen). Cells were treated with glutamate $(2 \mathrm{mM})$ in the presence or absence of peptides or siRNA for $12-14 \mathrm{~h}$, followed by fixation with $4 \%$ PFA and DAPI counterstained for the nuclei. We distinguished three categories of mitochondria based on their morphology: category I, long, tubular mitochondria; category II, short tubules or large round organelles; category III, small fragmented mitochondria. ${ }^{25,26,28}$ For each condition at least 500 cells were counted without knowledge of the treatment history. Images were collected with a DMI6000B fluorescence microscope, equipped with a DCF360FX-camera (Leica, Wetzlar, Germany).

Mitochondrial membrane potential measurements by flow cytometry. Loss of mitochondrial membrane potential was determined using the membrane potential-dependent dye TMRE (Invitrogen) and JC-1 reduction according to the manufacture's protocol (Mitoprobe, Invitrogen). ${ }^{25-27,41}$ The dye intake was analyzed by subsequent flow cytometry or epifluorescence microscopy. TMRE and JC-1 fluorescence was analyzed using FACScan (BD Bioscience). At least 10000 events were counted for each sample. Measurements were performed in triplicates and are representative of at least three independent experiments. Changes of the mitochondrial membrane potential $(\Delta \psi \mathrm{m})$ in isolated mitochondria were detected by the DIOC6(3) (Molecular probes, Life technologies, Carlsbad, CA, USA) fluorescence-based assay. Intact mitochondria $(\sim 25 \mu \mathrm{g})$, prepared as previously reported, ${ }^{42}$ were incubated with $20 \mathrm{nM}$ DIOC6(3) dye in white 96-well plates. As a positive control for a complete loss of $\Delta \psi \mathrm{m}$, CCCP $(50 \mu \mathrm{M})$ protonophore was applied on intact mitochondria. $\Delta \psi \mathrm{m}$ was analyzed by a FLUOstar Optima fluorescence plate reader (BMG Labtechnologies GmbH). CsA, used as a positive control, was added at a concentration of $5 \mu \mathrm{M}$ (SigmaAldrich, no. 3662). Measurements were performed in triplicates and are representative of at least three independent experiments.

Intracellular $\mathrm{Ca}^{2+}$ concentration detection. Intracellular $\mathrm{Ca}^{2+}$ concentration was assessed using Fluo-4 AM in 96-well plates according to the manufacturer's protocol (Invitrogen). HT-22 cells transiently transfected with peptides were seeded in 96-well plates. After $24 \mathrm{~h}$ of growing, cells were treated with $2 \mathrm{mM}$ glutamate for $12 \mathrm{~h}$. Intracellular $\mathrm{Ca}^{2+}$ was detected by adding Fluo-4 $\mathrm{AM}$ at a concentration of $5 \mu \mathrm{M}$ for $30 \mathrm{~min}$ to the medium. After the washing step, the fluorescence of each well was determined with an automated FLUOstar Optima reader (BMG Labtechnologies $\mathrm{GmbH}$ ) using an excitation wavelength of $485 \mathrm{~nm}$ and an emission wavelength of $520 \mathrm{~nm}$.

Prolyl isomerase activity assay. The PPlase activity of CypA was measured as measuring the catalysis of the cis-trans interconversion of cis Suc-Ala-Ala-Pro-Phe-4-pNA substrate (Sigma, no. S7388) in a coupled assay with $\alpha$-chymotrypsin. ${ }^{19} \alpha$-Chymotrypsin $(21 \mu \mathrm{M})$ (Sigma-Aldrich, no. 6423) was preincubated with the CypA protein $(0.2 \mu \mathrm{M})$, with two doses $(0.2$ and $2 \mu \mathrm{M})$ of AIF(370-394) peptide and then with the substrate $(22 \mu \mathrm{M})$. CsA at concentrations of 0.2 and $2 \mu \mathrm{M}$ were used as positive controls in the experiments. Experiments were performed three times. The hydrolysis of the 4-nitroanilide in the cis substrate is limited in rate by the cis-trans isomerization at Ala-Pro and was followed by the increase in absorbance at $390 \mathrm{~nm}$.

Statistical analysis. All data are given as mean \pm S.D. For statistical comparison between two groups, Student's $t$-test was used assuming a normal distribution of the respective data. Multiple comparisons were performed by ANOVA followed by Scheffé's post hoc test. Calculations were made with the WinStat standard statistical software package (Robert Fitch Software, Bad Krozingen, Germany). A statistically significant difference was assumed at ${ }^{*} P<0.05,{ }^{* *} P<0.01,{ }^{* *} P<0.001$.

\section{Conflict of Interest}

The authors declare no conflict of interest.

Acknowledgements. We thank Alexander Seiler (Roche Diagnostics GmbH) for providing the XCELLigence system, Dr. Julia Grohm and Mrs. Katharina Elsässer for the excellent technical support. Furthermore, we thank Mrs. Emma Esser for careful editing of the manuscript. This work has been supported by 'The National Biophotonics and Imaging Platform Ireland (NBIPI), career enhancement and mobility programme (CEMP) a Marie Curie co-funded scheme with the Irish Higher Education Authority (HEA) Program for Third Level Institutions Cycle 4 and the Italian National Research Council'. The project was also partly supported by FIRB MERIT project no. RBNE08NKH7 and 'PROGETTO CAMPUS' from Campania Region to MR.

\section{Author Contributions}

ND carried out the experiments, performed data analysis, and drafted the manuscript. ND, NP, MR and CC participated in the design and coordination of the study and edited the manuscript. CR performed western blot and FACS analysis on CypA-downregulated cells. PLS performed the peptide synthesis. AMD supported $\mathrm{ND}$ in performing imaging experiments. All authors read and approved the final manuscript.

1. Hangen E, Blomgren K, Bénit $P$, Kroemer G, Modjtahedi N. Life with or without AIF. Trends Biochem Sci 2010; 35: 278-287.

2. Sevrioukova IF. Apoptosis-inducing factor: structure, function, and redox regulation. Antioxid Redox Signal 2011; 14: 2545-2579.

3. Polster BM. AIF, reactive oxygen species, and neurodegeneration: a "complex" problem. Neurochem Int 2013; 62: 695-702.

4. Vahsen N, Candé C, Brière JJ, Bénit $\mathrm{P}$, Joza N, Larochette $\mathrm{N}$ et al. AIF deficiency compromises oxidative phosphorylation. EMBO J 2004; 23: 4679-4689.

5. Cheung EC, Joza N, Steenaart NA, McClellan KA, Neuspiel M, McNamara S et al. Dissociating the dual roles of apoptosis-inducing factor in maintaining mitochondrial structure and apoptosis. EMBO J 2006; 25: 4061-4073.

6. Cao G, Clark RS, Pei W, Yin W, Zhang F, Sun FY et al. Translocation of apoptosis-inducing factor in vulnerable neurons after transient cerebral ischemia and in neuronal cultures after oxygen-glucose deprivation. J Cereb Blood Flow Metab 2003; 23: 1137-1150.

7. Pallast S, Arai K, Pekcec A, Yigitkanli K, Yu Z, Wang X et al. Increased nuclear apoptosisinducing factor after transient focal ischemia: a 12/15-lipoxygenase-dependent organelle damage pathway. J Cereb Blood Flow Metab 2010; 30: 1157-1167.

8. Plesnila N, Zhu C, Culmsee C, Gröger M, Moskowitz MA, Blomgren K. Nuclear translocation of apoptosis-inducing factor after focal cerebral ischemia. J Cereb Blood Flow Metab 2004; 24: 458-466.

9. Thal SE, Zhu C, Thal SC, Blomgren K, Plesnila N. Role of apoptosis inducing factor (AIF) for hippocampal neuronal cell death following global cerebral ischemia in mice. Neurosci Lett 2011; 499: 1-3.

10. Culmsee C, Zhu C, Landshamer S, Becattini B, Wagner E, Pellecchia M et al. Apoptosis-inducing factor triggered by poly(ADP-ribose) polymerase and Bid mediates neuronal cell death after oxygen-glucose deprivation and focal cerebral ischemia. J Neuroscience 2005; 25: 10262-10272.

11. Slemmer JE, Zhu C, Landshamer S, Trabold R, Grohm J, Ardeshiri A et al. Causal role of apoptosis-inducing factor for neuronal cell death following traumatic brain injury. Am J Pathol 2008; 173: 1795-1805.

12. Piao CS, Loane DJ, Stoica BA, Li S, Hanscom M, Cabatbat R et al. Combined inhibition of cell death induced by apoptosis inducing factor and caspases provides additive neuroprotection in experimental traumatic brain injury. Neurobiol Dis 2012; 46: 745-758.

13. Candé C, Vahsen N, Kouranti I, Schmitt E, Daugas E, Spahr C et al. AIF and cyclophilin A cooperate in apoptosis-associated chromatinolysis. Oncogene 2004; 23: 1514-1521.

14. Zhu C, Wang X, Deinum J, Huang Z, Gao J, Modjtahedi N et al. Cyclophilin A participates in the nuclear translocation of apoptosis-inducing factor in neurons after cerebral hypoxiaischemia. J Exp Med 2007; 204: 1741-1748.

15. Handschumacher RE, Harding MW, Rice J, Drugge RJ, Speicher DW. Cyclophilin: a specific cytosolic binding protein for cyclosporin A. Science 1984; 226: 544-547.

16. Goldner FM, Patrick JW. Neuronal localization of the cyclophilin A protein in the adult rat brain. J Comp Neurol 1996; 372: 283-293.

17. Montague JW, Hughes Jr FM, Cidlowski JA. Native recombinant cyclophilins A, B, and C degrade DNA independently of peptidylprolyl cis-trans-isomerase activity. Potential roles of cyclophilins in apoptosis. J Biol Chem 1997; 272: 6677-6684.

18. Zhang XC, Wang WD, Wang JS, Pan JC. PPlase independent chaperone-like function of recombinant human Cyclophilin A during arginine kinase refolding. FEBS Lett 2013; 587: 666-672.

19. Gurbuxani S, Schmitt E, Cande C, Parcellier A, Hammann A, Daugas E et al. Heat shock protein 70 binding inhibits the nuclear import of apoptosis-inducing factor. Oncogene 2003; 22: 6669-6678.

20. Fukui M, Song JH, Choi J, Choi HJ, Zhu BT. Mechanism of glutamate-induced neurotoxicity in HT22 mouse hippocampal cells. Eur J Pharmacol 2009; 617: 1-11.

21. Artus C, Boujrad H, Bouharrour A, Brunelle MN, Hoos S, Yuste VJ et al. AlF promotes chromatinolysis and caspase-independent programmed necrosis by interacting with histone H2AX. EMBO J 2010; 29: 1585-1599.

22. Guo X. Surface plasmon resonance based biosensor technique: a review. J Biophotonics 2012; 5: 483-501.

23. Susin SA, Lorenzo HK, Zamzami N, Marzo I, Snow BE, Brothers GM et al. Molecular characterization of mitochondrial apoptosis-inducing factor. Nature 1999; 397: 441-446. 
24. $\mathrm{Ke} \mathrm{H}$. Similarities and differences between human cyclophilin $\mathrm{A}$ and other beta-barre structures. Structural refinement at 1.63A resolution. J Mol Biol 1992; 228: 539-550.

25. Grohm J, Plesnila N, Culmsee C. Bid mediates fission, membrane permeabilization and perinuclear accumulation of mitochondria as a prerequisite for oxidative neuronal cell death. Brain Behav Immun 2010; 24: 831-838.

26. Grohm J, Kim SW, Mamrak U, Tobaben S, Cassidy-Stone A, Nunnari J et al. Inhibition of Drp1 provides neuroprotection in vitro and in vivo. Cell Death Differ 2012; 19: 1446-1458.

27. Petit PX, Susin SA, Zamzami N, Mignotte B, Kroemer G. Mitochondria and programmed cell death: back to the future. FEBS Lett 1996; 396: 7-13.

28. Tobaben S, Grohm J, Seiler A, Conrad M, Plesnila N, Culmsee C. Bid-mediated mitochondrial damage is a key mechanism in glutamate-induced oxidative stress and AlF-dependent cell death in immortalized HT-22 hippocampal neurons. Cell Death Differ 2011; 18: 282-292.

29. Smiley ST, Reers M, Mottola-Hartshorn C, Lin M, Chen A, Smith TW et al. Intracellular heterogeneity in mitochondrial membrane potentials revealed by a J-aggregate-forming lipophilic cation JC-1. Proc Natl Acad Sci USA 1991; 88: 3671-3675.

30. Xu J, Hao Z, Gou X, Tian W, Jin Y, Cui S et al. Imaging of reactive oxygen species burs from mitochondria using laser scanning confocal microscopy. Microsc Res Tech 2013; 76 612-617.

31. Pinton P, Giorgi C, Siviero R, Zecchini E, Rizzuto R. Calcium and apoptosis: ER-mitochondria Ca2 + transfer in the control of apoptosis. Oncogene 2008; 27: 6407-6418.

32. Utkina-Sosunova IV, Niatsetskaya ZV, Sosunov SA, Ratner VI, Matsiukevich D, Ten VS et al. Nelfinavir inhibits intra-mitochondrial calcium influx and protects brain against hypoxicischemic injury in neonatal mice. PLoS One 2013; 8: e62448.

33. Cao G, Xing J, Xiao X, Liou AFK, Yin XM, Clark RSB et al. Critical role of calpain I in mitochondrial release of apoptosis-inducing factor in ischemic neuronal injury. $J$ Neurosci 2007; 27: 9278-9293.

34. Wang P, Heitman J. The cyclophilins. Genome Biol 2005; 6: 226.
35. Yu SW, Wang Y, Frydenlund DS, Ottersen OP, Dawson VL, Dawson TM. Outer mitochondrial membrane localization of apoptosis-inducing factor: mechanistic implications for release. ASN Neuro 2009; 1: e00021.

36. Tremper-Wells B, Vallano ML. Nuclear calpain regulates $\mathrm{Ca} 2+$-dependent signaling via proteolysis of nuclear $\mathrm{Ca} 2+/$ calmodulin-dependent protein kinase type IV in cultured neurons. J Biol Chem 2005; 280: 2165-2175.

37. Fields GB, Noble RL. Solid phase peptide synthesis utilizing 9-fluorenylmethoxycarbonyl amino acids. Int J Pept Protein Res 1990; 35: 161-214.

38. Johnsson B, Lofas S, Lindquist G. Immobilization of proteins to a carboxymethyldextranmodified gold surface for biospecific interaction analysis in surface plasmon resonance sensors. Anal Biochem 1991; 198: 268-277.

39. Dolga AM, Letsche T, Gold M, Doti N, Bacher M, Chiamvimonvat N et al. Activation of $\mathrm{KCNN} 3 / \mathrm{SK} / \mathrm{K}(\mathrm{Ca}) 2.3$ channels attenuates enhanced calcium influx and inflammatory cytokine production in activated microglia. Glia 2012; 60: 2050-2064.

40. Myszka DG. Analysis of small-molecule interactions using Biacore S51 technology. Anal Biochem 2004; 329: 316-323.

41. Diemert S, Dolga AM, Tobaben S, Grohm J, Pfeifer S, Oexler E et al. Impedance measurement for real time detection of neuronal cell death. J Neurosci Methods 2012; 203: 69-77.

42. Öxler EM, Dolga A, Culmsee C. AIF depletion provides neuroprotection through a preconditioning effect. Apoptosis 2012; 17: 1027-1038.

(c) (i) () $\Theta$ Cell Death and Disease is an open-access journa published by Nature Publishing Group. This work is licensed under a Creative Commons Attribution-NonCommercialNoDerivs 3.0 Unported License. To view a copy of this license, visit http://creativecommons.org/licenses/by-nc-nd/3.0/

Supplementary Information accompanies this paper on Cell Death and Disease website (http://www.nature.com/cddis) 